\title{
Enjoying the Limits of Musculoskeletal Ultrasound
}

\author{
Emre ATA, Adem ERBİROL, Alparslan Bayram ÇARLI
}

Department of Physical Medicine and Rehabilitation, Haydarpaşa Sultan Abdülhamid Training and Research Hospital, İstanbul, Turkey

An 80-year-old female patient was examined due to complaint of neck pain over the last year which has aggravated recently. She denied history of trauma. Her medical history indicated that she was taking some medications for hypertension and coronary artery disease. Physical examination was compatible with cervical osteoarthritis with limited cervical range of motion in all directions and tenderness to palpation. Laboratory findings including complete blood count, erythrocyte sedimentation rate, $\mathrm{C}$-reactive protein, serum calcium, phosphorus, parathyroid hormone, and vitamin $\mathrm{D}$ levels were within normal ranges. On radiological evaluation, cervical X-ray revealed a calcified mass in the left mid-paravertebral region with cervical degenerative changes (Figure 1). At first glance, a calcification inside the cervical muscles was suspected. Ultrasonographic examination of the cervical region revealed the presence of intraluminal calcification at the level of the bifurcation of the left common carotid artery (Figure 2a-c). The patient was referred to neurology department for being at risk for stroke.

Carotid arteries are the major vascular structures that deliver blood to brain. A blockage in carotid arteries can lead to stroke which is typically caused by atherosclerosis. ${ }^{1}$ The arterywall thickens as a result of invasion and deposit of white blood cells and proliferation of intimalsmooth-muscle cell creating a fatty plaque which is known as atherosclerosis. ${ }^{2}$ These deposits also contain cellular waste, cholesterol, and triglycerides with often occurring calcification. ${ }^{2}$ Therefore, paravertebral calcifications seen on X-ray might be inside the vessels, particularly in the elderly. Complications of the carotid artery calcification should be kept in mind, so that the patient can be referred to the relevant departments before occurrence of catastrophic consequences such as stroke. Ultrasonography should be the method of choice in confirming the diagnosis. ${ }^{3}$

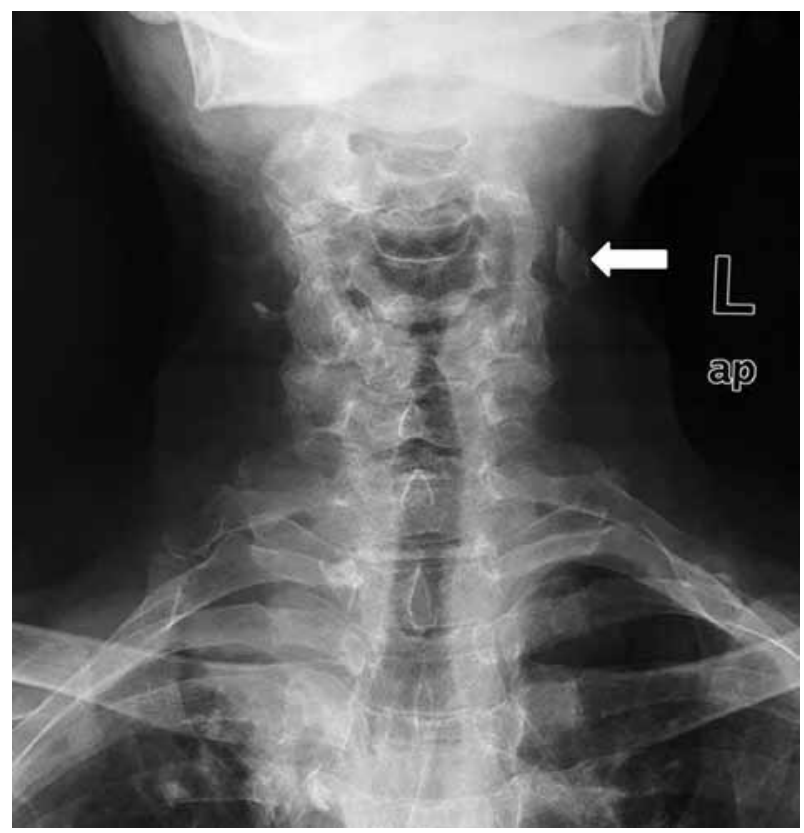

Figure 1. Posteroanterior cervical X-ray of patient illustrating a calcified mass (arrow) in left mid-paravertebral region with cervical degenerative changes. 

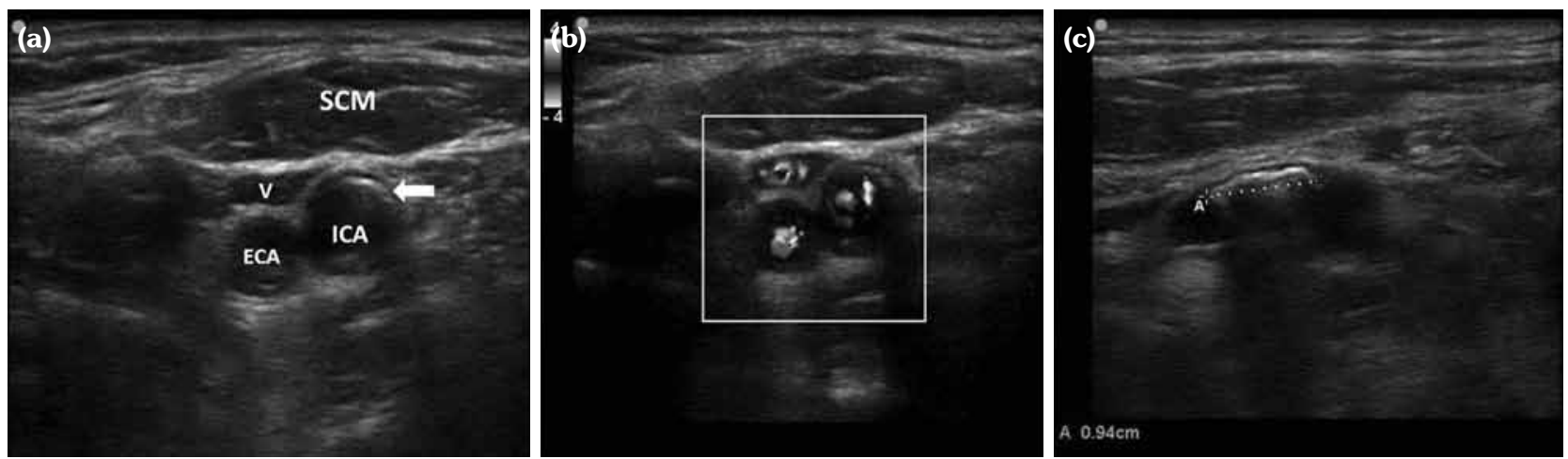

Figure 2. Axial ultrasound images of patient revealing presence of intraluminal calcification (arrow) at level of bifurcation of left common carotid artery (a) without and (b) with Doppler flow and (c) longitudinal view of calcification. SCM: Sternocleidomastoid muscle; ICA: Internal carotid artery; ECA: External carotid artery; V: Internal jugular vein.

Lastly, ultrasound gives not only an opportunity to evaluate musculoskeletal pathologies, but also offers visualization of a wide range of nearby tissues such as vessels and organs. Physicians who are dealing with musculoskeletal conditions and performing ultrasound should conduct a thorough musculoskeletal ultrasound examination including nearby vessels.

\section{Declaration of conflicting interests}

The authors declared no conflicts of interest with respect to the authorship and/or publication of this article.

\section{Funding}

The authors received no financial support for the research and/or authorship of this article.

\section{REFERENCES}

1. Calvet D, Mas JL. Recent advances in carotid angioplasty and stenting. Int J Stroke 2016;11:19-27.

2. Singh RB, Mengi SA, Xu YJ, Arneja AS, Dhalla NS. Pathogenesis of atherosclerosis: A multifactorial process. Exp Clin Cardiol 2002;7:40-53.

3. Kim JH, Youn HJ, Kim GH, Moon KW, Yoo KD, Kim CM. The Clinical Significance of Separate Measurements of Carotid Arterial Wall to Assess the Risk Factor for Atherosclerosis. J Cardiovasc Ultrasound 2016;24:48-54. 